\title{
Dermatite alérgica sazonal em ovinos deslanados no Nordeste do Brasil ${ }^{1}$
}

\author{
Roseane de A. Portela², Kézia S. Carvalho², Silvia M.M Ahid ${ }^{3}$, Maria L. Felippe-Bauer ${ }^{4}$ \\ e Franklin Riet-Correa ${ }^{2 *}$
}

\begin{abstract}
Portela R.A., Carvalho K.S., Ahid S.M.M., Felippe-Bauer M.L. \& Riet-Correa F. 2012. [Sazonal allergic dermatitis in hair sheep from northeastern Brazil.] Dermatite alérgica sazonal em ovinos deslanados no Nordeste do Brasil. Pesquisa Veterinária Brasileira 32(6):471-476. Hospital Veterinário, Centro de Saúde e Tecnologia Rural, Campus de Patos, Universidade Federal de Campina Grande, Patos, PB 58700-970, Brazil. E-mail: franklin.riet@pq.cnpq.br

Seasonal allergic dermatitis is reported in a flock of 40 hair sheep of the Santa Inês breed, in the county of Jucurutú, State of Rio Grande do Norte, in the semiarid region of Northeastern Brazil. For the epidemiologic and clinical observations the farm was visited periodically from 2007 to 2010 . The flock was raised extensively in a Paddock crossed by the Piranhas river, and had also a permanent pond. Between 2007 and 2009, 13 (32.5\%) sheep out of 40 were affected. The lesions were observed during the raining season, regressed total or partially during the dry season, and reappeared in the next raining period. Sheep removed to other region recovered. At the end of 2009, all affected sheep were removed from the flock. Three new cases appeared in 2010. The skin of the affected sheep was whitish, irregularly thickened, with alopecia, crusts, and intense pruritus. Those lesions were localized more frequently in the head (ears and periocular and frontal regions) but in some animals the dorsum and croup were also affected. Histologic lesions of the epidermis were hyperkeratosis, acanthosis, hypergranulosis, and moderate spongiosis. The dermis showed infiltration by eosinophils, macrophages and plasma cells, mainly perivascular. The hair follicles showed keratosis and the sudoriparous glands were dilated. No changes were observed in the differential blood count. In April and June 2010 insects were captured by the use of CDC light trap. Forty three out of 110 dipterous captured were identified as Culicoides insignis Lutz. It is concluded that the disease is a seasonal allergic dermatitis associated with $C$. insignis bites.
\end{abstract}

INDEX TERMS: Dermatitis, allergic dermatitis, Type I hypersensitivity, Culicoides insignis, skin diseases, semiarid, Santa Inês sheep.

RESUMO.- Dermatite alérgica sazonal foi diagnosticada em um rebanho de 40 ovinos da raça Santa Inês no município de Jucurutú, Estado de Rio Grande do Norte. Para o estudo epidemiológico e observação dos sinais clínicos a propriedade foi visitada periodicamente entre 2007 e 2010 . Os ovi-

\footnotetext{
${ }^{1}$ Recebido em 24 de outubro de 2011.

Aceito para publicação em 3 de dezembro de 2011.

${ }^{2}$ Hospital Veterinário, Centro de Saúde e Tecnologia Rural (CSTR), Campus de Patos da Universidade Federal de Campina Grande (UFCG), Patos, PB 58700-970, Brasil.*Autor para correspondência: roseanevet@hotmail.com

${ }^{3}$ Departmento de Ciência Animal, Universidade Federal Rural do Semiárido (UFERSA), BR $110 \mathrm{Km} \mathrm{47,} \mathrm{Mossoró,} \mathrm{RN} \mathrm{59625-900,} \mathrm{Brasil.}$

${ }^{4}$ Laboratório de Diptera, Instituto Oswaldo Cruz - Fiocruz, Av. Brasil 4365, Rio de Janeiro, RJ 21040-900, Brasil.
}

nos eram criados extensivamente em campo nativo cortado pelo rio Piranhas e com um açude permanente. Entre 2007 e 2009 adoeceram $13(32,5 \%)$ ovinos de um total de 40 . As lesões eram observadas durante a época da chuva e regrediam total ou parcialmente durante a seca, reaparecendo no próximo período chuvoso. Os animais que foram retirados da área se recuperaram. No final de 2009 foram eliminados os animais susceptíveis e três novos casos apareceram em 2010. A pele apresentava lesões alopécicas, crostosas, enrugadas, esbranquiçadas e com intenso prurido, localizados na região da cabeça (orelhas, ao redor dos olhos e região frontal), região dorsal do corpo e garupa. Histologicamente, a epiderme apresentou hiperqueratose, acantose, hipergranulose e moderada espongiose. Na derme havia 
infiltrado inflamatório, principalmente perivascular, composto por eosinófilos, macrófagos e plasmócitos. Observou-se queratose de folículos pilosos e dilatação das glândulas sudoríparas. No hemograma, os valores de todos os animais estavam dentro dos valores normais. Em abril e junho de 2010 foram realizadas capturas de insetos com armadilhas luminosas CDC, sendo 110 dípteros capturados, dos quais 43 foram identificados como Culicoides insignis Lutz. Considerando que esta espécie tem sido associada à dermatite alérgica em outras regiões conclui-se que a doença é uma dermatite alérgica sazonal associada à picada de $C$. insignis.

TERMOS DE INDEXAÇÃO: Dermatite, dermatite alérgica, hipersensibilidade Tipo I, Culicoides insignis, doenças de pele, semiárido, ovinos Santa Inês.

\section{INTRODUÇ̃̃o}

0 primeiro relato da dermatite alérgica sazonal ocorreu no verão de 1840 na França (Henry \& Bory 1937), desde então esta dermatite, descrita primariamente em equídeos, é estudada em todo o mundo. Caracteriza-se por prurido e lesões alopécicas e crostosas distribuídas pela linha média do dorso, cabeça, inserção da cauda e patas (Fadok \& Greiner 1990). À medida que os surtos surgiram em diversos países, principalmente de clima temperado e subtropical, a doença recebeu diversas denominações conforme algumas particularidades incluindo o caráter sazonal e pruriginoso. Entre elas, "summer eczema" na Noruega (Halldórdsóttir \& Larsen 1991), "sweet itch" na Suécia e na Irlanda (Brostrom et al. 1987, Baker \& Quinn 1978),"dermatite estival recidivante crônica dos equídeos" no Brasil (Portugal et al. 1996), ou ainda "culicoides hipersensitivity" devido ao díptero pertencente ao gênero Culicoides apontado como um dos causadores da doença (Yeruham et al. 1993, Ginn et al. 2007).

A dermatite alérgica sazonal ocorre em outras espécies de animais domésticos incluindo ovinos, bovinos, muares e caprinos, comumente associada à hipersensibilidade a Culicoides spp. (Yeruham et al. 1993, Souza et al. 2005, Corrêa et al. 2007, Macêdo et al. 2008). Porém outros gêneros parecem estar envolvidos como Aedes scapularis, A. serratus, Culex spp. e Psophora ferox (Ferreira 2007), Mansonia spp. (Schild et al. 1993), Phlebotomus pernicious (Ordeix et al. 2000) e dípteros do gênero Simulium e Hipplates (Barbosa et al. 2011). Em ovinos pode estar ainda relacionada à picada de Ctenocephalides felis (Yeruham et al. 2004). A histopatologia das lesões e testes intradérmicos com substratos de Culicoides spp. sugerem que a reação dermal não é inteiramente mediada por IgE (hipersensibilidade tipo I) estando envolvido também hipersensibilidade tipo IV( Barbet et al. 1990).

$\mathrm{Na}$ espécie ovina há relatos da doença na Inglaterra (Connan \& Lloyd 1988), Israel (Yeruham et al. 1993, 2004) e Espanha (Ordeix et al. 2000). No Brasil ocorre nas regiões Sul (Schild et al. 1993, Souza et al. 2005, Corrêa et al. 2007, Ferreira 2007), Norte (Barbosa et al. 2011, Vinhote et al. 2010) e um caso isolado foi descrito na região nordeste (Macêdo et al. 2008). Este trabalho objetiva descrever dermatite alérgica sazonal em um rebanho de ovinos da raça
Santa Inês no município de Jucurutú, Estado de Rio Grande do Norte.

\section{MATERIAL E MÉTODOS}

O estudo foi realizado em uma propriedade do município de Jucurutú, localizado na Microrregião Vale do Açu, do Estado do Rio Grande do Norte, que possui um clima quente e semiárido. As estações do ano nesta região assim como em todo o território nordestino, são divididas em estação chuvosa, entre os meses de janeiro-fevereiro a maio-junho e estação seca nos demais meses do ano. A temperatura media é de $28,1^{\circ} \mathrm{C}$ e a umidade relativa de $66 \%$. 0 município tem coordenadas $06^{\circ} 02^{\prime} 02^{\prime \prime}$ de latitude sul e $37^{\circ} 01^{\prime} 12^{\prime \prime}$ longitude oeste e é banhado pelo Rio Piranhas que o atravessa na direção SW/N. A precipitação pluviométrica anual normal é de $820 \mathrm{~mm}$ (Emparn 2010).

0 estudo transcorreu durante os anos de 2007 a 2010. Em 2007, foram feitas observações dos sinais clínicos nos animais afetados e realizadas biopsias incisionais em quatro deles, para auxiliar no diagnóstico. A partir de visitas na propriedade em 2008 e 2009, 13 ovinos enfermos foram numerados (no 1-13) e uma fêmea adulta e sadia $\left(\mathrm{n}^{\circ} 14\right)$ foi utilizada como controle para os exames de sangue mensais realizados durante o ano de 2009. Em abril e junho de 2010 foram realizadas capturas de insetos para avaliação do vetor.

Para monitoramento e avaliação das lesões, seis animais (Ovinos 1-5 e 7) foram retirados da área afetada e transportados para o Hospital Veterinário (HV), localizado no município de Patos no estado da Paraíba, onde ficavam em baias, soltos durante o período da manha e recebiam volumoso e concentrado. Biopsias incisionais periódicas foram feitas em três ovinos (Ovinos 1, 2 e 5) para caracterização macroscópica e microscópica das lesões. Utilizou-se pré-anestésico com xilazina a $2 \%$ intravenosa, anestesia local com xilocaína a $2 \%$, incisionando-se com bisturi fragmentos de aproximadamente $1 \mathrm{~cm}^{2}$ de pele da orelha, fixados em solução de formalina a $10 \%$, processados em parafina, coradas por hematoxilina-eosina (HE) e Azul de Toluidina. Dos seis ovinos levados para o HV, cinco retornavam a fazenda de origem após ser constatada a regressão total das lesões. 0 restante retornou após 180 dias, mesmo sem regressão total das lesões.

Para a realização de hemograma, amostras mensais de sangue de todos os animais afetados (Ovinos 1-13) e controle (Ovino 14) foram coletadas da veia jugular através de tubos a vácuo contendo etilenodiaminotetraacético (EDTA). Esfregaços sanguíneos foram confeccionados e corados pelo método Panótico.

As capturas dos insetos foram realizadas utilizando-se armadilha luminosa CDC associada à isca animal, uma ovelha jovem, mestiça da raça Santa Inês. Entre 17:00 e 20:00 horas a ovelha era mantida em pé em um curral na propriedade afetada pela enfermidade. Os insetos atraídos pelo animal e pela luz da armadilha ficavam retidos no interior da mesma. Os espécimes, após depósito em recipientes próprios, eram mortos com éter etílico e mantidos à seco com naftalina para envio à Coleção de Ceratopogonidae, Laboratório de Diptera do Instituto Oswaldo Cruz, Rio de Janeiro, para identificação.

\section{Epidemiologia}

\section{RESULTADOS}

A propriedade possuía um rebanho de aproximadamente 40 ovinos sob sistema extensivo. A área de pastejo abrangia plantas nativas, incluindo Mimosa tenuiflora (jurema preta), Combretum leprosum (mufumbo), Croton sonderions (marmeleiro), Pilosoceres gounellei (xique-xique) e Aspidosperma pyrifolium (pereiro). Plantas tóxicas que 
causam fotossensibilização não foram observadas. 0 campo onde ocorria a doença é atravessado pelo Rio Piranhas, além de contar com um açude permanente, que não seca durante o período seco. Segundo o proprietário, a doença vinha ocorrendo anualmente durante as épocas de chuva desde 2005 e os animais doentes permaneciam com lesões durante todo o ano. As lesões se tornavam mais pronunciadas no período chuvoso e regrediam parcialmente no período da seca.

No início do estudo, em 2007, havia na fazenda dois jumentos, 12 vacas e 40 ovinos. Durante os anos de 2007 e 2008 havia sete $(17,5 \%)$ ovinos doentes, dos quais dois foram retirados do rebanho. Em 2009 permaneciam doentes os cinco animais observados no ano anterior (Ovinos 1-5). Além disso, adoeceram mais quatro animais na época da chuva (janeiro a junho) e outros quatro no mês de setembro, totalizando oito animais (Ovinos 6-13) doentes durante o ano de 2009. Dos 13 animais enfermos, base do estudo, e que correspondem a $32,5 \%$ do total do rebanho, nove eram fêmeas adultas, um cordeiro, um carneiro e duas fêmeas jovens de até um ano. No final de 2009 foram descartados seis ovinos que tinham sido afetados anteriormente.

\section{Sinais clínicos}

Os quatro ovinos estudados em 2007 e os Ovinos 1-5, 7 e 8 apresentavam lesões bilaterais na cabeça, principalmente na região periocular, inserção e face dorsal da orelha e região frontal (Fig.1). Um dos ovinos observados em 2007 tinha também lesões extensas em toda linha dorsal e lateral do corpo e na região axilar direita (Fig.1). Outro ovino observado em 2007 e os Ovinos 3 e 4 apresentavam, também, lesões na região lombo-sacral formando um triângulo entre as tuberosidades coxais e a inserção da cauda. 0 Ovino 3 apresentava lesões no dorso da região cervical proximal. 0 Ovino 6 foi afetado apenas na região dorsal da orelha. 0 Ovino 9 apresentou lesão focal no dorso acima da cauda e lesão unilateral da face dorsal da orelha. Os Ovinos 10-13 tinham lesões discretas apenas na região periocular superior.

Essas lesões eram irregulares, com superfície esbranquiçada, apresentando crostas e pele enrugada e engrossada (liquenificação). Em algumas áreas havia edema subcu- tâneo e, em outras, lesões avermelhadas com escoriações e exsudato. Nas áreas adjacentes os pelos estavam opacos e quebradiços e se desprendiam com facilidade ao se fazer uma delicada fricção. O Ovino 1 teve opacidade da córnea e infecção secundária com exsudato purulento no canal lacrimal. 0 Ovino 8 teve miíase na fossa lacrimal. Os Ovinos 1-3 e 8 apresentavam-se inquietos com repetidos abanos de orelhas, coçando-se em tocos e cercas além de marcada perda de peso.

Os Ovinos 1-5 e 7 começaram a apresentar regressão das lesões 15-20 dias após serem retirados da fazenda. Inicialmente houve diminuição da edemaciação e das crostas da pele. 0 0vino 3, após 45 dias, apresentava apenas áreas com pelos opacos e áreas cicatriciais, principalmente na região próxima da inserção da cauda. Os Ovinos 5 e 7, após 54 dias, tiveram regressão completa das lesões e a pele e pelos estavam normais. Aos 99 dias, o Ovino 2 estava com regressão completa das lesões, porém na região periocular notava-se acentuada presença de pelos brancos e áreas alopécicas na inserção das orelhas (Fig.2). 0 Ovino 4, confinado na zona urbana de Jurucutú por duas semanas, apresentou melhora da lesões nesse período, e regressão total das mesmas 30 dias após ser trasladado para o HV, permanecendo com alopecia parcial. O Ovino 1 permaneceu com lesões caracterizadas por áreas alopécicas e pele enrugada na região da inserção da orelha e na área periocular, com predomínio de pelos brancos mesmo após 180 dias no HV.

Dos seis animais (Ovinos 1-5 e 7) que retornaram á fazenda após a regressão das lesões dois apresentaram lesões após o retorno: o Ovino 1 no qual não houve regressão completa das lesões e o Ovino 2, que após a regressão das lesões voltou a presentar dermatite alérgica no mês de setembro, quando foram observados três novos casos da doença.

\section{Patologia}

O exame histopatológico das biopsias dos quatro animais observados em 2007 e dos Ovinos 1, 2 e 5 revelaram, na epiderme, severa hiperqueratose, acantose e hipergranulose focalmente extensas e moderada espongiose. Em algumas áreas observavam-se pústulas intraepiteliais. $\mathrm{Na}$
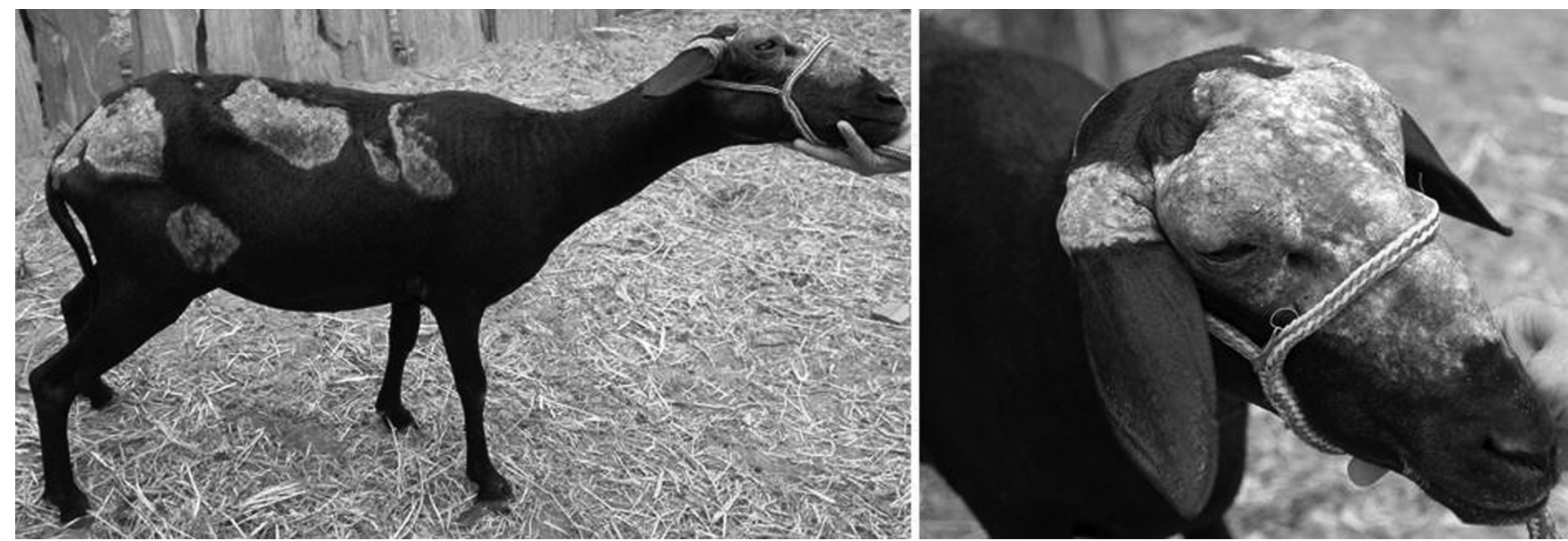

Fig.1. Ovino com lesões de alopecia e dermatite em diversas regiões do corpo. 

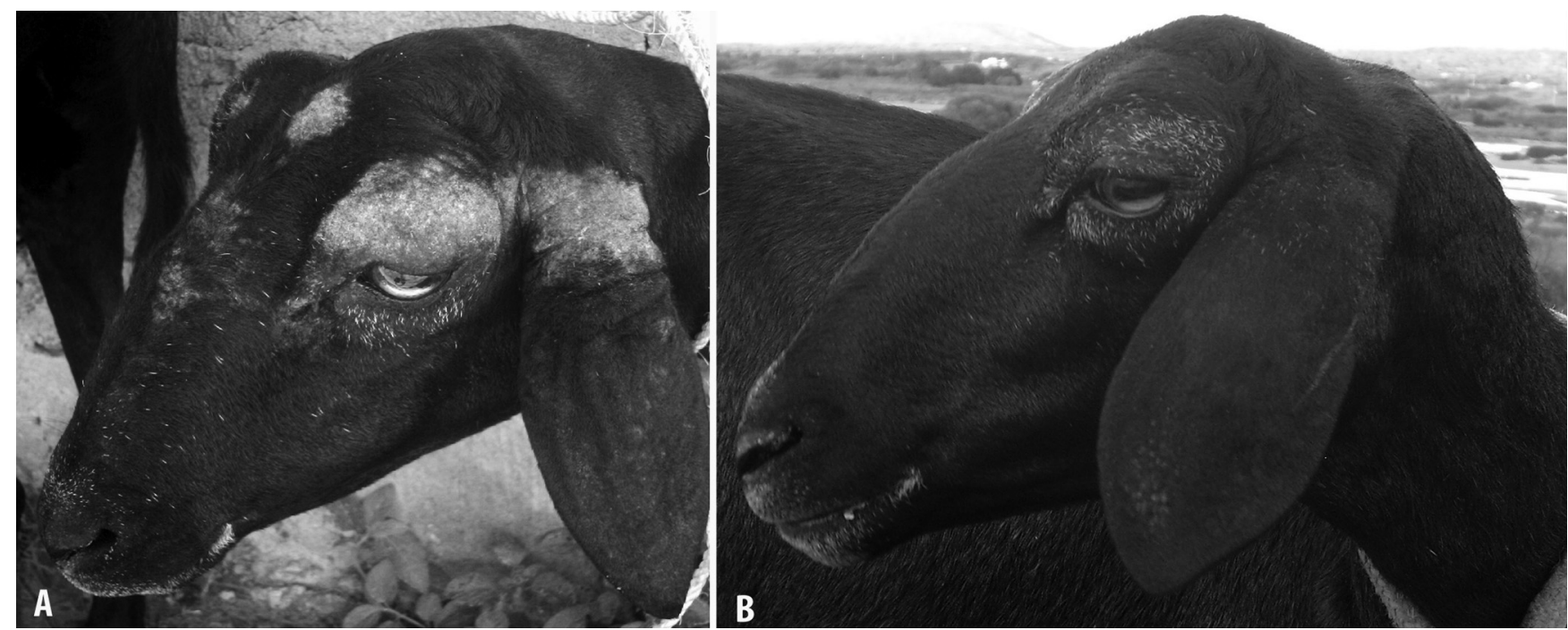

Fig.2. (A) Ovino 2, fotografado em 24 de abril de 2009 e (B) em 30 de Julho do mesmo ano. Observa-se regressão total das lesões e presença de pelos brancos nas áreas onde havia dermatite.

derme havia intenso infiltrado inflamatório, preferentemente perivascular, composto por eosinófilos, macrófagos, plasmócitos e poucos linfócitos (Fig3A,B). As lesões eram mais marcadas na derme superficial do que na profunda. Havia degeneração das fibras colágenas com aumento da

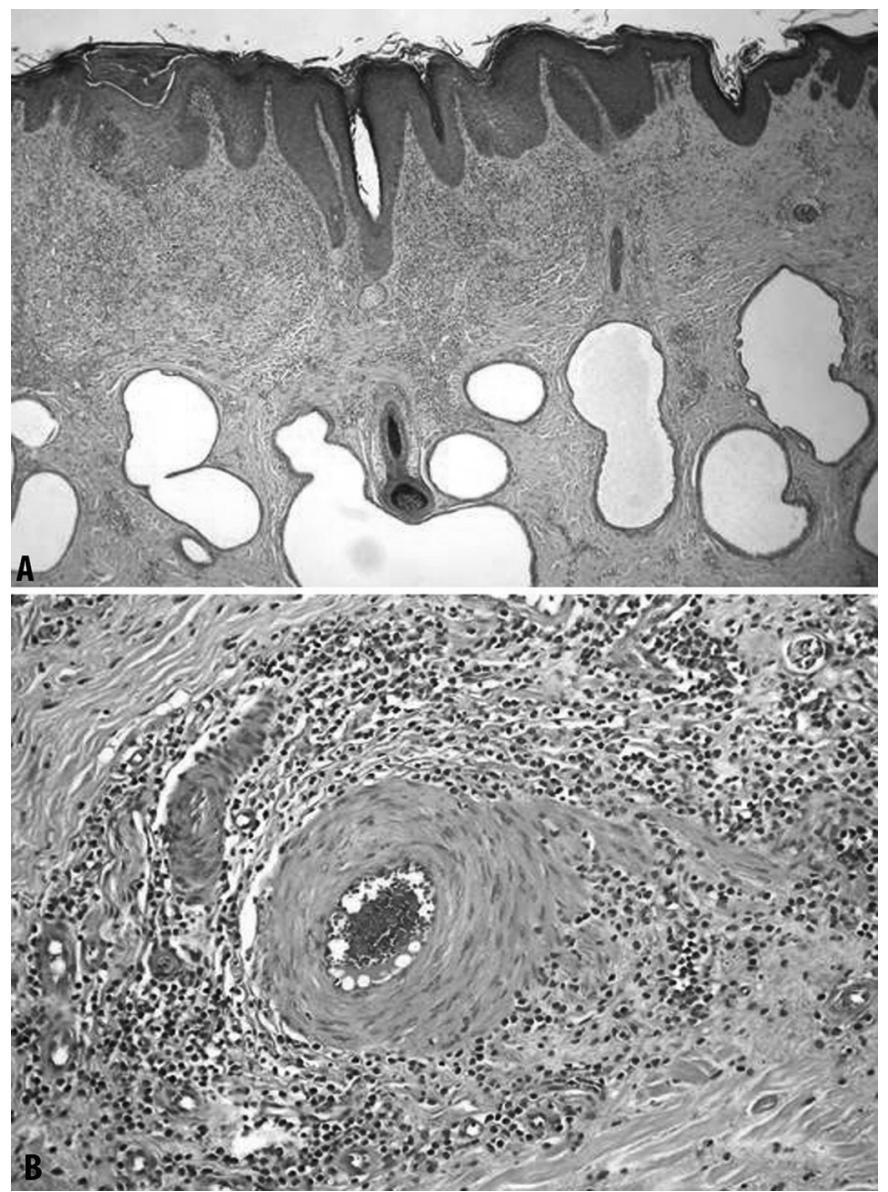

Fig.3. (A,B) Corte histológico da pele mostrando severa dermatite, principalmente perivascular. (A) Dilatação das glândulas sudoríparas com hiperqueratose e acantose da epiderme. HE, (A) obj.10x, (B) obj.20x. eosinofilia, acúmulo de queratina no interior de folículos pilosos e dilatação das glândulas sudoríparas (Fig.3A).

Nas biopsias realizadas para constatar a regressão das lesões, o Ovino 5 revelou regressão das mesmas observando-se discreto infiltrado inflamatório na derme composto de plasmócitos e linfócitos. No Ovino 1, no qual não houve recuperação completa das lesões, a última biópsia demonstrou discreto infiltrado mononuclear perivascular e hipergranulose. Pela coloração de Azul de Toluidina não foram vistos mastócitos em nenhuma biopsia. Nos hemogramas realizados não foram observados alterações, e os eosinófilos não ultrapassaram $4 \%$ nos animais afetados e controles.

\section{Coleta e identificação dos insetos}

No total foram capturados 110 dípteros. Destes, 66 exemplares pertencem a família Chironomidae e 44 a família Ceratopogonidae. Como os quironomídeos não apresentam hábito hematofágico, seu encontro na armadilha sugere que eles tenham sido atraídos pela luz. Dentre os ceratopogonídeos encontrados, um espécime pertence a um gênero predador de insetos e 43 exemplares pertencem a espécie Culicoides insignis Lutz, incriminada na transmissão da dermatite alérgica, bem como de Língua Azul em ruminantes na América Central e do Sul.

\section{DISCUSSÃO E CONCLUSÕES}

O diagnóstico de dermatite alérgica sazonal foi realizado com base nos achados epidemiológicos, clínicos e histopatológicos, semelhantes aos descritos na dermatite alérgica em ovinos e pela identificação de Culicoides insignis Lutz (Connan \& Lloyd 1988, Yeruham et al. 1993, Souza et al. 2005, Corrêa et al. 2007).

No Brasil dermatite alérgica causada por $C$. insignis foi diagnosticada anteriormente no Rio Grande do Sul nas raças Hampshire, Corriedale, Ideal, Texel, e cruzas (Schild et al. 1993, Corrêa et al. 2007). Mais recentemente casos de dermatite alérgica em ovinos deslanados, da raça Santa Inês, no Pará, foram associados à presença de Simulium e Hippelates (Barbosa et al. 2011). 
Em outros países a doença é relatada em ovinos das raças Assaf, Merino e Black Welsh Moutain (Yeruham et al.1993, Winter 1999). Segundo Yeruham et al. (2004) há uma sensibilidade diferenciada entre as raças, destacando a raça Merino como a mais sensível. Neste trabalho foi demonstrada a sensibilidade da raça deslanada Santa Inês, que é raça de corte mais difundida no nordeste brasileiro. Casos de dermatite alérgica, não associados à Culicoides foram observados também na raça Santa Inês, no Pará (Barbosa et al. 2011), enquanto que, nesse mesmo Estado, em uma criação mista de Texel e Santa Inês foi observado dermatite alérgica apenas em ovinos da raça Texel (Vinhote et al. 2010). Macêdo et al. (2008) relatou um caso isolado de dermatite alérgica em junho de 2005 em um ovino da raça Cariri na região nordeste do Brasil.

A prevalência da doença é variável, podendo ser de $4 \%$ a $6 \%$ até $60 \%$ a $80 \%$ (Ordeix et al. 2000, Ferreira 2007). Neste trabalho o percentual de animais afetados nos anos 2008 e 2009 foi de 17,5\% e 32,5\%, respectivamente, semelhante à prevalência observada por Souza et al. (2005) que foi de $10 \%$ a $50 \%$, que detectaram, também, um aumento de animais afetados no ano sequencial. 0 aumento de casos clínicos durante o ano de 2009 pode ser devido á ocorrência de condições ambientais favoráveis ao desenvolvimento de mosquitos ou a presença de novos animais susceptíveis. Em casos de hipersensibilidade tipo I, as lesões podem ocorrer somente após o segundo contato com o alérgeno (Abbas et al. 2008). Como resultado da eliminação dos animais que tinham sido afetados anteriormente houve uma marcada diminuição da morbidade em 2010. Esses resultados sugerem que uma das principais formas de controle da enfermidade é a eliminação dos animais susceptíveis. Marti et al. (1992) em um estudo em equinos sugere que a hipersensibilidade dermal por alérgenos é influenciada pela hereditariedade. Em conseqüência, a eliminação de animais susceptíveis leva a uma diminuição da ocorrência da doença (Corrêa et al. 2007).

Neste trabalho foi evidenciado que a doença é sazonal, acontecendo principalmente na estação de chuvas, quando a população de Culicoides é maior. No entanto, novos casos ocorreram, também, no mês de setembro de 2009, época em que havia menor número de Culicoides. Um fator que pode contribuir para a ocorrência da doença, ainda na época seca, é que, devido à escassez de alimento, os animais buscam alimentos verdes nas áreas mais úmidas, próximo ao rio e o açude da propriedade, ambientes propícios ao desenvolvimento dos Culicoides (Santarém et al. 2010). Em climas temperados a doença ocorre, principalmente, na primavera e verão, regredindo total ou parcialmente no inverno (Yeruham et al. 1993, Souza et al. 2005, Corrêa et al. 2007, Ferreira 2007).

Em casos já relatados de dermatite alérgica sazonal em ovinos lanados, além das lesões na cabeça, foram observadas lesões abaixo do abdômen, úbere, tetas, patas e lábios (Connan \& Lloyd 1988, Yeruham et al. 1993, Souza et al. 2005, Corrêa et al. 2007). As áreas hipersensíveis do abdômen, úbere e patas de ovinos correspondem às áreas picadas por Culicoides obsoletus Meigen (Yeruham et al. 1993). Para esta espécie Conann \& Lloyd (1988) consideraram a área de cabeça e uma área de $20-40 \mathrm{~cm}$ entre o ovino e o chão como preferenciais. Corrêa et al (2007) observaram que a picada de $C$. insignis afeta as mesmas áreas em ovinos lanados da raça Hampshire Down. A predileção do local de picada de várias espécies de Culicoides é provavelmente determinada pela coloração e diferentes temperaturas das várias partes do corpo, tipo de pelo e proximidade e densidade dos vasos sanguíneos (Braverman 1988, Yeruham et al. 1993). Em nosso estudo, os ovinos afetados da raça Santa Inês, mostraram dermatite localizada exclusivamente na região da cabeça (frontal, periocular, orelhas) e parte dorsal e lateral do corpo. Isso pode ser devido às características raciais, incluindo a cor preta e por ser deslanada, o que facilita a atividade hematofágica dos Culicoides, diferentemente dos ovinos lanados, onde os insetos procuram as partes baixas e mais livres de pelos. Outra espécie de Culicoides, $C$. furens Poey, já foi identificada na Paraíba, porém não relacionada com a dermatite alérgica (Araújo Lima et al. 2004).

0 emagrecimento e o autotraumatismo aqui relatado geralmente são sinais decorrentes da característica marcante da doença que é o intenso prurido (Connan \& Lloyd 1988). Souza et al. (2005) e Corrêa et al. (2007) macroscopicamente caracterizaram dois padrões de lesões: uma crônica, com alopecia descamativa e crostosa e edema; e outra aguda na qual além da alopecia observa-se eritema acentuado associado a grande quantidade de pápulas, pústulas e colaretes epidérmicos. Nos ovinos deste surto não se observaram eritema, pápulas e pústulas, mesmo em animais afetados recentemente.

As alterações histológicas nos ovinos deste surto são semelhantes às descritas por outros autores para a dermatite alérgica sazonal, características de uma reação alérgica de hipersensibilidade tipo I (Corrêa et al. 2007, Schild et al. 1993) e provavelmente tipo IV (Souza et al. 2005, Corrêa et al. 2007). 0 único achado diferente dos demais, também relatado por Macêdo et al. (2008), foi a dilatação das glândulas sudoríparas. No estudo da regressão das lesões constatou-se que o infiltrado mononuclear perivascular mesmo que discreto ainda permanece nos animais após a regressão das lesões. Estas células podem permanecer maduras no tecido por dias a semanas no tecido conjuntivo (Abbas et al. 2008).

Na contagem diferencial de leucócitos não foram encontradas alterações significativas e, principalmente, não houve eosinofilia, sugerindo que este exame não deve ser utilizado para o diagnóstico da doença. Contrariamente, Yeruham et al. (1993) observaram eosinofilia, com mais de $18 \%$ de eosinófilos, em ovinos afetados. Segundo Tizard (2008), a proporção de eosinófilos entre os leucócitos sanguíneos variam grandemente em função da presença de parasitas, habitat e período de coleta.

O diagnóstico diferencial da dermatite alérgica sazonal associada à Culicoides em ovinos deslanados no nordeste deve incluir outras dermatites alérgicas causadas por produtos químicos, medicamentos e outros artrópodes, sarna, micoses, deficiência de zinco, fotossensibilização e dermatofiloses (Macêdo et al. (2008).

As medidas de controle e prevenção da dermatite alér- 
gica sazonal devem incluir, quando possível, a seleção de animais resistentes, mediante identificação e descarte dos animais afetados. Como foi comprovado neste trabalho, a retirada dos animais das áreas onde ocorre a doença leva à regressão das mesmas. A estabulação de animais no final da tarde até a próxima manhã, longe da vegetação e das fontes de água, pode amenizar a gravidade das lesões e possivelmente $\mathrm{o}$ aparecimento de novos casos.

Agradecimentos.- Ao Conselho Nacional de Desenvolvimento Científico e Tecnológico (CNPq, Bolsa de Mestrado), ao Laboratório de Patologia Animal (UFCG) e ao produtor rural Ivonildo Ferreira pelo suporte para o desenvolvimento desse estudo.

\section{REFERÊNCIAS}

Abbas A.K., Lichtman A.H. \& Pillai S. 2008. Imunologia Celular e Molecular. $6^{\mathrm{a}}$ ed. Elsevier, Rio de Janeiro, p.442-461.

Araújo Lima R.C., Almeida V.F. \& Athayde A.C. 2004. Ocorrência de Culicoides furens (Diptera: Ceratopogonidae) no município de Lagoa Seca, Paraíba. XXXI Congresso Brasileiro de Medicina Veterinária, São Luis, Maranhão.

Baker K.P. \& Quinn P.J. 1978. A report on clinical aspects and histopathology of sweet itch. Equine Vet. J. 10(4):243-248.

Barbet J.L., Bevier B. \& Greiner E.C. 1990. Specific immunotherapy in the treatment of Culicoides hypersensitive horses: a double-blind study. Equine Vet. J. 22(4):232-235.

Barbosa J.D., Albernaz T.T., Oliveira C.M.C., Duarte M.D., Oliveria C.H.S., Brito M.F. \& Silva A.G.M.S. 2011. Dermatite alérgica à picada de insetos em ovinos no estado do Pará. Pesq. Vet. Bras. 31(2):117-120

Braverman Y. 1988. Preferred landing sites of Culicoides species (Diptera:Ceratopogonidae) on horse in Israel and its relevance to summer seasonal recurrent dermatitis (sweet itch). Equine Vet. J. 20(6):426-429.

Brostrom H., Larsson A. \& Troedsson M. 1987. Allergic dermatitis (sweet itch) of Icelandic horses in Sweden: an epidemiological study. Equine Vet. J. 19(3):229-236.

Connan R.M. \& Lloyd S. 1988. Seasonal allergic dermatitis in sheep. Vet. Rec. 123:335-337.

Corrêa T.G., Ferreira J.M., Riet-Correa G., Ruas J.L., Schild A.L., Riet-Correa F., Guimarães A. \& Felippe-Bauer M.L. 2007. Seasonal allergic dermatits in sheep in southern Brazil causaed by Culicoides insignis (Diptera: Ceratopogonidae). Vet. Parasitol. 145:181-185.

Empresa de Pesquisa Agropecuária do Rio Grande do Norte (EMPARN). 2010. Disponivel em <http://www.emparn.rn.gov.br> Acessado em 12 nov. 2009.

Fadok V.A. \& Greiner E.C. 1990. Equine insect hypersensitivity: Skin test and biopsy results correlated with clinical data. Equine Vet. J. 22(4):236240.
Ferreira J.L.M. 2007. Dermatite alérgica sazonal, p.624-626. In: Riet-Correa F., Schild A.L., Lemos R.A.A. \& Borges J.R.J. (Eds.), Doenças de Ruminantes e Eqüinos. Vol.2. $3^{\mathrm{a}}$ ed. Pallotti, Santa Maria.

Ginn P.E., Mansell J.E.K.L. \& Rakich P.M. 2007. Skin and appendages, p.553781. In: Maxie M.G. (Ed.), Pathology of Domestic Animals. Vol.2. $5^{\text {th }}$ ed. W.B. Saunders, London.

Henry A. \& Bory L. 1937. Dermatose estivale recidivante du cheval: pathology et therapeutique. Rec. Méd. Vét. 113:65-78.

Halldórdsóttir S. \& Larsen H.J. 1991. An epidemiological study of summer eczema on Icelandic horses in Norway. Equine Vet. J. 23(4):296-299.

Macêdo J.T.S.A., Riet-Correa F., Dantas A.F.M. \& Simões S.V.D. 2008. Doenças de pele em caprinos e ovinos no semi-árido brasileiro. Pesq. Vet. Bras. 28(12):633-642.

Marti E., Gerber H. \& Lazary S. 1992. On the genetic basis of equine allergic diseases: II. Insect bite dermal hypersensitivity. Equine Vet. J. 24(2):113-117.

Ordeix L., Solano-Galego L., Rabanal R., Buade M., Fondati A. \& Ferrer L. 2000. Seasonal allergic dermatitis in sheep due to Phlebotomus perniciosus. Vet. Dermatol. 11(1):14-40.

Portugal M.A.S.C., Guerra J.L., Baldassi L., Fernandes N.S. \& Calil E.M.B. 1996. Dermatite estival recidivante em eqüinos. Arqs Inst. Biológico, São Paulo, 63(1):1-6.

Santarém M.C.A., Confalonieri U.E.C. \& Felippe-Bauer M.L. 2010. Diversity of Culicoides (Diptera: Ceratopogonidae) in the National Forest of Caxiuanã, Melgaço, Pará State, Brazil. Revta Pan-Amaz. Saude 1(4):2933.

Schild A.L., Pereira D.I.B., Ladeira S., Ruas L., Ferreira J.L.M. \& Pereira O.A.P. 1993. Diagnósticos realizados no ano de 1992 pelo Laboratório Regional de Diagnóstico e comentários sobre algumas doenças. Bolm Laboratório Regional de Diagnóstico, Pelotas, no.13, p.9-24.

Souza T.M., Fighera R.A., Piazer J.V., Barros C.L. \& Irigoyen L.F. 2005. Dermatite alérgica sazonal em ovinos. Ciência Rural 35(2):475-477.

Tizard I.R. 2008. Imunologia Veterinária. 8ae ed. Elsevier, Rio de janeiro. 587p.

Vinhote W.M.S., Almeida M.B., Cerqueira V.D., Oliveira C.A., Paredes L.J.A., Tavares C.C.S. \& Riet-Correa G. 2010. Dermatite alérgica sazonal em ovinos no estado do Pará. Anais do encontro nacional de diagnóstico veterinário, Campo Grande, MS. Disponível em <http://www.unigran.br/ interbio/vol4_num1/arquivos/Endivet> Acesso em 16 jul. 2011.

Winter A.C. 1999. Severe seasonal dermatitis in a flock of black Welsh mountain sheep. Proc. Sheep Vet. Society 23:105-108.

Yeruham I., Braverman Y. \& Orgad U. 1993. Field observations in Israel on hypersensitivity in cattle, sheep and donkeys caused by Culicoides. Aust. Vet. J. 70:348-352.

Yeruham I., Perl S. \& Braverman Y. 2004. Seasonal allergic dermatitis in sheep associated with Ctenocephalides and Culicoides bites. Vet. Dermatol. 15:377-380. 